\title{
EVARTS GRAHAM
}

Professor Evarts Graham died at the age of 73 on March 4, 1957, in Barnes Hospital, St. Louis, the hospital in which he had made all his great surgical contributions.

$\mathrm{He}$ was an honorary member of both the Thoracic Society and of the Association of Thoracic Surgery of Great Britain and Ireland. His great achievements in surgery brought him honorary membership of many learned societies throughout the world, numerous honorary degrees and many other distinctions, including, of course, the highest surgical honours in his own country.

His contributions to general surgery, notably of the biliary apparatus, were alone outstanding, but he is somewhat better known for his fundamental work on thoracic problems. At the end of the first world war the very high mortality of the respiratory infections associated with the influenza epidemics led to the appointment of a special commission of enquiry by the United States Army. Graham was responsible for the basic contributions to our knowledge of pleural suppuration which emerged from the enquiry.

His interest in thoracic disease, and especially lung suppuration, continued. His "cautery pneumonectomy," although now only of historical interest, was an important operation in the 1920 s. From this work arose the Thoracic Surgical Unit at Barnes Hospital which soon became the Mecca of all thoracic surgeons.

In April, 1933, he performed the first successful pneumonectomy for carcinoma ; the patient is still alive and well 24 years later. The success of this case stood out as a shining light to many thoracic surgeons struggling at that time with the difficulties, anxieties, and disappointments of operations on patients with bronchial carcinoma and served as an encouragement, the need of which may not be so much appreciated to-day when operations for the condition are largely routine.

Graham had the happy attribute of being able 
to inspire and direct the training and life work of the many young surgeons who were fortunate enough to act as his assistants. His trainees are to be found all over the world and several senior thoracic surgeons in Great Britain feel they owe almost everything to his influence.

His outstanding qualities led to his services being in demand for many activities outside his own hospital. He became the Elder Statesman of American surgery, and during the war nearly exhausted himself with extra work on government advisory committees.

His international commitments were also many and important. Recently he was President of the International Society of Surgery. He was Editor of the Journal of Thoracic Surgery from its inception in 1931 until his death. This alone was a notable achievement.
He was a frequent visitor to Great Britain and he was looked upon as a true friend and almost one of us. He was a man of very great personal charm and readily inspired affection.

In addition to being an honorary F.R.C.S. he was Lister Gold Medallist and his Lister Oration was on "Some Aspects of Bronchogenic Carcinoma."

In recent years he directed the statistical and experimental work in the United States that revealed the close relationship between cigarette smoking and bronchial carcinoma. Ironically he succumbed to the very disease he had done so much to alleviate. Happily the clinical course was insidious and the termination mercifully swift. Thus passed probably the greatest surgeon of this half-century and certainly the greatest thoracic surgeon of his time.

RusSell BROCK. 